\title{
First-Principles Calculations and Thermodynamic Assessment of the Li-Rh and Tl-Tm Systems
}

\author{
Yassine Djaballah, Ahmed Said Amer, Şule Uğur, Gökay Uğur, and Aissa Belgacem-Bouzida
}

\begin{abstract}
Thermodynamic modeling of the Li-Rh and Tl-Tm systems was carried out via a hybrid approach of CALPHAD (CALculation of PHAse Diagrams) and first-principles calculations. The enthalpies of formation of $\mathrm{LiRh}, \mathrm{LiRh}_{3}, \mathrm{Tl}_{3} \mathrm{Tm}$ TITm and $\mathrm{Tl}_{3} \mathbf{T m}_{5}$ are computed via first-principles calculations by using the VASP code. The CALPHAD assessment of $\mathrm{Li}-\mathrm{Rh}$ and Tl-Tm systems was then performed by considering both the first-principles computed enthalpies of formation and the experimental phase equilibrium data. The liquid phase was modeled with Redlich-Kister polynomial and the five intermetallics compounds were described as stoichiometric compounds. A consistent thermodynamic data set and phase diagrams for the Li-Rh and Tl-Tm systems are obtained.
\end{abstract}

Index Terms-CALPHAD, first-principles calculations, Li-Rh system, Tl-Tm system, phase diagrams.

\section{INTRODUCTION}

The alloy systems or intermetallic compounds composed of transition or rare earth metals have attracted much attention for the theoretical study of the solid state and for many industrial purposes, particularly in the fields of magnetism, energy and high technology [1].

The CALPHAD method, which is a powerful tool to cut down on cost and time during development of materials [2], effectively provides a clear guideline for materials design. In order to design high-performance alloys with rare earth elements, it is important to develop a thermodynamic database including transition and rare earth elements alloys.

In this work, the available experimental data of the $\mathrm{Li}-\mathrm{Rh}$ and $\mathrm{Tl}-\mathrm{Tm}$ systems are critically assessed and used to evaluate the model parameters defining the Gibbs energies of the phases in the systems. To supplement the experimental information, first-principles calculations of the formation enthalpies of the intermetallics compounds in this binary system are also included.

\section{EXPERIMENTAL DATA}

\section{A. Li-Rh System}

The Li-Rh has been reviewed by Sangster and Pelton[3].

Manuscript received March 24, 2015; revised July 16, 2015.This work was supported by (the Algerian General Direction for Scientific Research and Technological Development (PNR No. 8/u05/4532).

Yassine Djaballah, Ahmed Said Amer, and Aissa Belgacem-Bouzida are with the Laboratory of Physical and chemical study of materials (LEPCM), Physics Department, Faculty of Science, University of Batna, Algeria (e-mail: ydjaballah@yahoo.fr, ahmed.saidamer@yahoo.fr, bouzida.aissa@yahoo.fr).

Şule Uğur and Gökay Uğur are with Physics Department, Faculty of Science, Gazi University, 06500, Teknikokullar, Ankara, Turkey (e-mail: suleugur@gazi.edu.tr, gokay@gazi.edu.tr).
The assessed $\mathrm{Li}-\mathrm{Rh}$ phase diagram is based on very limited data and contains two compounds $\mathrm{LiRh}$ and $\mathrm{LiRh}_{3}$. No liquidus data have been published for this system. The evaluated phase diagram in Massalski [4] is given in Fig. 1. Magee [5] and Wheat et al. [6] performed some thermal analyses but no experimental details were given. The LiRh compound is prepared by direct reaction of the elements. A melting temperature of this compound is observed consistently at $2163 \mathrm{~K}$. This may be interpreted as a eutectic temperature. Donkersloot and Van Vucht [7]detected the compound LiRh3, which they characterized by X-Ray diffraction. The tentative congruent melting point of this compound is $1943 \mathrm{~K}$ [3]. The crystallographic structure of the compounds $\mathrm{LiRh}_{3}$ was determined by Donkersloot and Van Vucht [7], while that of the LiRh compounds is given by Sidhu et al. [8] (see Table I). The enthalpies of formation of the intermetallic compounds $\mathrm{LiRh}$ and $\mathrm{LiRh}_{3}$ were predicted by using the semi-empirical model of Miedema [9].

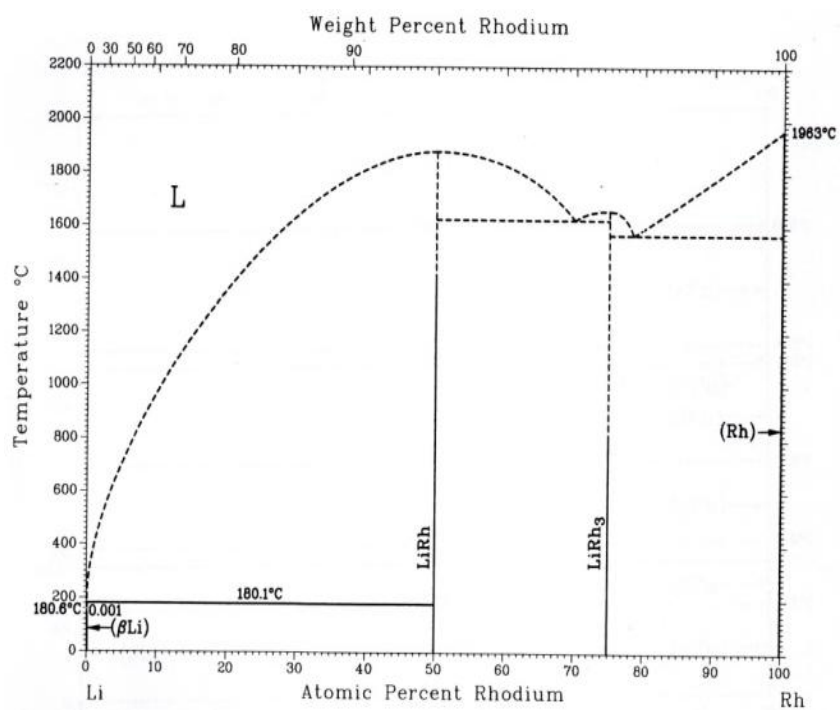

Fig. 1. Phase diagram of the Li-Rh system from Ref [4].

\section{B. Tl-Tm System}

An experimentally determined phase diagram is not known for the Tl-Tm system. Assuming similarity to La-Tl, Ce-Tl and Pr-Tl systems, Moffatt [10] has sketched a tentative phase diagram, which has been redrawn by Massalski [4] (Fig. 2). The Tl-Tm system consists of three terminal solution phases $\alpha \mathrm{Tl}, \beta \mathrm{Tl}$ and $\mathrm{Tm}$ and three intermetallic compounds $\mathrm{Tl}_{3} \mathrm{Tm}$, TlTm and $\mathrm{Tl}_{3} \mathrm{Tm}_{5}$. There are three eutectic reactions of the $\mathrm{L} \leftrightarrow(\beta \mathrm{Tl})+\mathrm{Tl}_{3} \mathrm{Tm}$ at about $573 \mathrm{~K}$, $\mathrm{L} \leftrightarrow \mathrm{TlTm}+\mathrm{Tl}_{3} \mathrm{Tm}$ and $\mathrm{L} \leftrightarrow \mathrm{Tl}_{3} \mathrm{Tm}_{5}+\mathrm{Tm}$, and a eutectoid reaction of the $\beta \mathrm{Tl} \leftrightarrow \alpha \mathrm{Tl}+\mathrm{Tl}_{3} \mathrm{Tm}$ at about $503 \mathrm{~K}$, and a peritectic reaction of the $\mathrm{L}+\mathrm{Tl}_{3} \mathrm{Tm}_{5} \leftrightarrow \mathrm{TlTm}$. The crystal structures of the $\mathrm{Tl}_{3} \mathrm{Tm}$, TlTm and $\mathrm{Tl}_{3} \mathrm{Tm}_{5}$ compounds are 
determined by Franceschi and Palenzona[11] and Moriarty et al. [12] and are listed in TableI. No experimental data on the thermodynamic properties is reported for the Tl-Tm system.

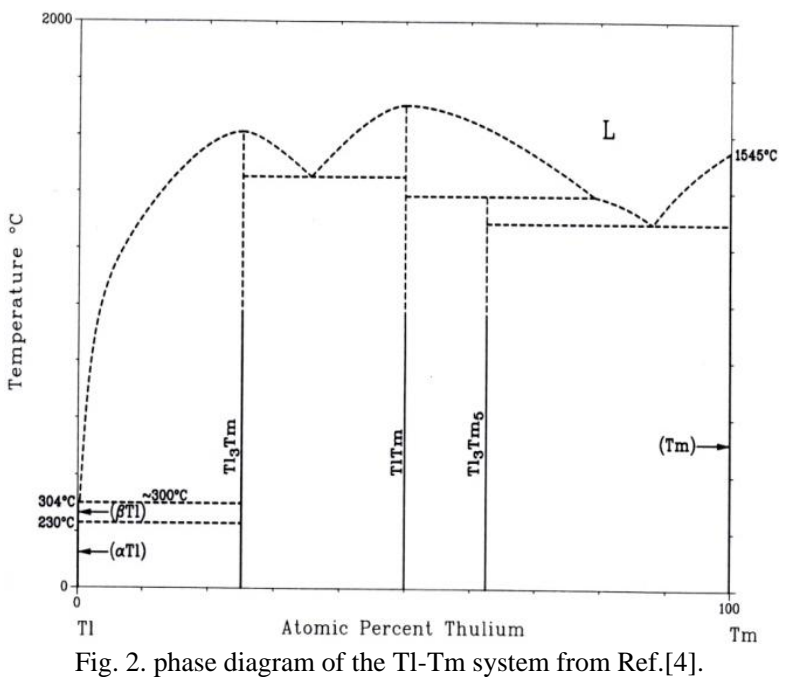

III. MODELING

\section{A. First Principles Calculation}

In order to enhance the reliability of thermodynamic assessment, first-principles calculations based on density functional theory (DFT) [13] are carried out using Vienna Ab-initio Simulation Package (VASP) [14] to get formation energy of compounds involved.

The energy of formation at $0 \mathrm{~K}$ of the compounds $\mathrm{LiRh}$, $\mathrm{LiRh}_{3}, \mathrm{Tl}_{3} \mathrm{Tm}$, TlTm and $\mathrm{Tl}_{3} \mathrm{Tm}_{5}$ compounds is obtained by the following equations:

$$
\Delta E\left(A_{x} B_{y}\right)=E\left(A_{x} B_{y}\right)-x E(A)-y E(B) .
$$

where $E\left(A_{x} B_{y}\right), E(A)$ and $E(B)$ are the total energy for $A_{x} B_{y}$, pure element $\mathrm{A}$ and $\mathrm{B}(\mathrm{A}=\mathrm{Li}$ or $\mathrm{Tl}$ and $\mathrm{B}=\mathrm{Rh}$ or $\mathrm{Tm})$ at $0 \mathrm{~K}$ respectively. At $0 \mathrm{~K}$, energy formation corresponds also to the enthalpy of formation.

The calculations are performed using the projected augmented wave (PAW) pseudo-potentials [15] with the Perdew-Burke-Ernzerhof [16] GGA for the exchangecorrelation potential. A plane wave cutoff energy of $300 \mathrm{eV}$ is used, a value that is more than 1.3 times greater than the highest plane wave energy cutoff of the elements in the both systems. An energy convergence criterion of $10^{-5} \mathrm{eV}$ for electronic structure self-consistency was used in the calculations. Brillouin zone integrations were performed using the Monkhorst-Pack k-point mesh scheme [17], and the total energy differences were converged to within $10^{-4} \mathrm{~J} / \mathrm{mol}$.

\section{B. Thermodynamic Models}

Pure elements: The Gibbs energy functions ${ }^{0} G_{i}^{\varphi}=G_{i}^{\varphi}-H_{i}^{S E R}(298.15 K)$ or the elements $i(i=\mathrm{Li}, \mathrm{Rh}, \mathrm{Tl}$ or $\mathrm{Tm}$ ) in the phase $\varphi$ is expressed by the following equation:

$$
{ }^{0} G_{i}^{\varphi}=a+b T+c T L n T+d T^{2}+e T^{3}+f T^{-1}+g T^{7}+h T^{-9}
$$

where $H_{i}^{S E R}(298.15 K)$ is the molar enthalpy of the element $i$ at $298.15 \mathrm{~K}$ in its standard element reference (SER) state. ${ }^{0} G_{i}^{\varphi}$ and $G_{i}^{\varphi}$ are the absolute and the relative Gibbs energy of the element $i$ in the $\varphi$ state, and $\mathrm{T}$ is the absolute temperature. In the present modeling, the Gibbs energies for pure elements were taken from the compilation by Dinsdale [18].

Intermetallic compounds:The intermetallic compounds in the Li-Rh and Tl-Tm systems present no solubility range according to the available experimental data. Thus, they have been treated as stoichiometric compounds:

The Gibbs energy of the $A_{p} B_{q}(A=L i, T 1$ and $B=R h, T m)$ intermediate phases, can be expressed as:

$$
G^{A_{p} B_{q}}=\Delta H_{f}^{A_{p} B_{q}}-T \Delta S_{f}^{A_{p} B_{q}}
$$

The enthalpy and entropy of formation ( $\Delta H_{f}^{A_{p} B_{q}}$ and $\left.\Delta S_{f}^{A_{p} B_{q}}\right)$ of the $A_{p} B_{q}$ phase were considered as temperature independent optimizing parameters.

Solution phase:The liquid phases in the two systems were modeled as substitutional solutions and the Gibbs energy is described by the following formalism:

$$
G^{\varphi}=\sum_{i} x_{i}{ }^{0} G_{i}^{\varphi}+G^{i d e}+G^{e x c}
$$

where $x_{i}$ is the molar fraction of the component $i$ in the $\varphi$ phase $(i=L i, R h, T l$ or $T m),{ }^{0} G_{i}^{\varphi}$ is the molar Gibbs energy of pure component in the $\varphi$ phase, which are taken from the compilation of Dinsdale [18]. The terms $G^{i d e}$ and $G^{e x c}$ stand for the molar Gibbs energy of ideal and excess mixing. The excess Gibbs energy $G^{e x c}$ can be expressed as an empirical Redlich Kister polynomial [19]:

$$
G^{e x c}=x_{A} x_{B} \sum_{v=0}^{n}{ }^{v} L_{A ; B}^{L i q}\left(x_{A}-x_{B}\right)^{v}
$$

whereas $G^{\text {ide }}$ can be calculated according the theoretical relationship

$$
G^{i d e}=R T\left[x_{A} \operatorname{Ln}\left(x_{A}\right)+x_{A} \operatorname{Ln}\left(x_{A}\right)\right]
$$

where $R$ is the gas constant, $x_{A}$ and $x_{B}$ are the mole fraction of elements $\mathrm{Li}$ or $\mathrm{Tl}$ and $\mathrm{Rh}$ or $\mathrm{Tm}$ respectively. ${ }^{v} L_{A ; B}^{L i q}$ is the $v$ interaction parameters expressed as ${ }^{v} L_{A ; B}^{L i q}=A_{v}+T B_{v}$ and $A_{v}$ and $B_{v}$ are model parameters to be evaluated.

\section{Assessment Procedure}

Most of the experimental data mentioned above were used in the thermodynamic evaluation. The optimization was carried out by using our computer program [20], [21]. Each piece of the selected information was given a certain weight by personal judgment, and changed by trial and error during the assessment, until most of the selected experimental information was reproduced within the expected uncertainty limits. All the parameters were evaluated together to give the best description of the system.

\section{RESUlTS AND DisCUSSION}

Lattice parameters and enthalpies of formation for $\mathrm{Li}-\mathrm{Rh}$ and Tl-Tm compounds, obtained from first principles 
calculations, are reported in Table I. The calculated lattice parameters are in good agreement with experimental data, with a maximum difference of about $1.5 \%$. Table II lists the optimized thermodynamic parameters of each phase in the Li-Rh and Tl-Tm systems.

TABLE I: CRYSTAL STRUCTURES DATA AND ENTHALPIES OF FORMATION OF THE LI-RH AND TL-TM SYSTEMS

\begin{tabular}{|c|c|c|c|c|c|}
\hline \multirow{3}{*}{$\begin{array}{c}\text { Phase } \\
\text { LiRh }\end{array}$} & \multirow{3}{*}{$\begin{array}{c}\begin{array}{c}\text { Pearson symbol and } \\
\text { Space group }\end{array} \\
h P 2 \\
(P-6 m 2)\end{array}$} & \multicolumn{3}{|c|}{ Lattice parameters (nm) } & \multirow{2}{*}{$\begin{array}{r}\text { Ref. } \\
{[8]}\end{array}$} \\
\hline & & 0.2649 & 0.2649 & 0.4359 & \\
\hline & & 0.2658 & 2.6578 & 0.4360 & $\begin{array}{l}\text { This } \\
\text { work }\end{array}$ \\
\hline \multirow{2}{*}{$\mathrm{LiRh}_{3}$} & \multirow{2}{*}{$\begin{array}{c}o I 8 \\
(\text { Imm } 2)\end{array}$} & 0.2658 & 0.8602 & 0.4657 & [7] \\
\hline & & 0.2670 & 0.8641 & 0.4667 & $\begin{array}{l}\text { This } \\
\text { work }\end{array}$ \\
\hline \multirow{2}{*}{$\mathrm{Tl}_{3} \mathrm{Tm}$} & \multirow{2}{*}{$c P 4(P m-3 m)$} & 0.4655 & 0.4655 & 0.4655 & {$[12]$} \\
\hline & & 0.4760 & 0.4761 & 0.4760 & $\begin{array}{l}\text { This } \\
\text { work }\end{array}$ \\
\hline \multirow{2}{*}{$\mathrm{TITm}$} & \multirow{2}{*}{$\begin{array}{c}c P 2 \\
(P m-3 m)\end{array}$} & 0.3670 & 0.3670 & 0.367 & {$[12]$} \\
\hline & & 0.3768 & 0.3768 & 0.3768 & $\begin{array}{l}\text { This } \\
\text { work }\end{array}$ \\
\hline \multirow{2}{*}{$\mathrm{Tl}_{3} \mathrm{Tm}_{5}$} & \multirow{2}{*}{$h P 16\left(P 6_{3} / \mathrm{mcm}\right)$} & 0.8798 & 0.8798 & 0.6495 & [11] \\
\hline & & 0.8936 & 0.8936 & 0.6547 & $\begin{array}{l}\text { This } \\
\text { work }\end{array}$ \\
\hline
\end{tabular}

TABLE II: THE OPTIMIZED PARAMETERS OF LI-RH AND TL-TM SYSTEMS

\begin{tabular}{ccc}
\hline \hline System & Phases & Thermodynamic parameters \\
\hline & Liquid & ${ }^{0} L_{L i ; R h}^{L i q}=-34966+5.266 * T$ \\
Li-Rh & LiRh & $\Delta G^{L i R h}=-17481-2.737 * T$ \\
& $\mathrm{LiRh}_{3}$ & $\Delta G^{L i R h 3}=12009-0.695 * T$ \\
\hline & Liquid & ${ }^{0} L_{T l ; T m}^{L i q}=-49408+25.079 * T$ \\
& $\mathrm{Tl}_{3} \mathrm{Tm}$ & $\Delta G^{T l 3 T m}=-13340-2.131 * T$ \\
$\mathrm{Tl}-\mathrm{Tm}$ & $\mathrm{TlTm}$ & $\Delta G^{T 3 T m}=-22434+2.359 * T$ \\
& & \\
& $\mathrm{Tl}_{3} \mathrm{Tm}$ & $\Delta G^{T l 3 T m 5}=-22771+5.045 * T$ \\
\hline \hline
\end{tabular}

Fig. 3 shows the calculated Li-Rh phase diagram. Comparison of the calculated invariant reactions with the experimental and predicted ones in this system is listed in Table III. All reactions are reproduced with experiment uncertainties. Table IV and Fig. 4 shows the evaluated enthalpies of formation of the $\mathrm{LiRh}$ and $\mathrm{LiRh}_{3}$ intermetallics by Calphad method together with the predicted data obtained by the Miedema model [9], as well as the calculated values determined by first principles calculations. Our calculations are acceptable in comparison with the predicted ones, if we take into account the large uncertainties of the Miedema model.

Calculated Tl-Tm phase diagram is shown in Fig. 5. Comparison of the calculated invariant equilibria temperatures and compositions with experimental and calculated ones is listed in Table V. A satisfactory agreement is noted between our result and the experimental. The enthalpies of formation of the Tl-Tm intermetallic compounds calculated in this work are presented in Fig. 6 and
Table IV. As we can see that the convex hull for compounds is stable.

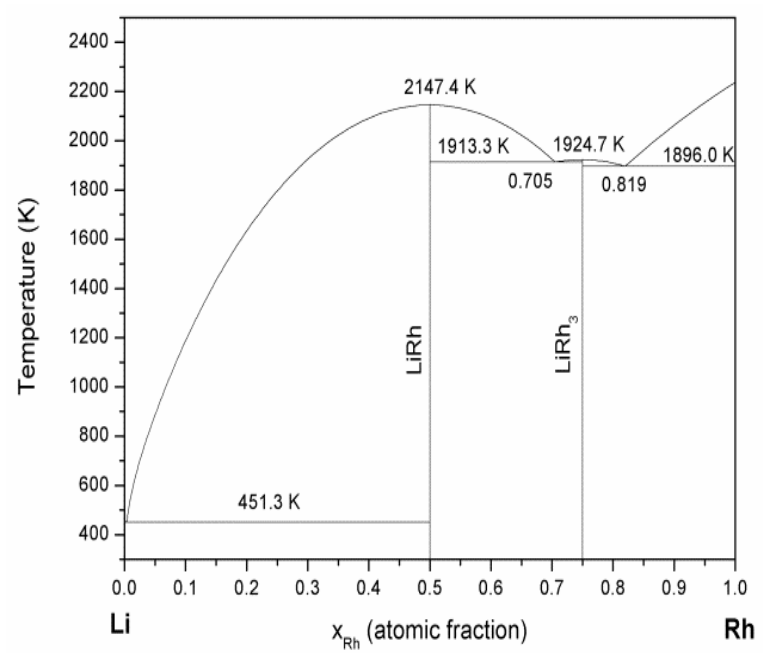

Fig. 3. Calculated phase diagram of the Li-Rh system.

TABLE III: THE INVARIANT REACTIONS IN THE LI-RH SYSTEM

\begin{tabular}{|c|c|c|c|c|c|}
\hline \multirow{2}{*}{ Reaction } & \multirow{2}{*}{$\begin{array}{l}\text { Type of } \\
\text { reaction }\end{array}$} & \multicolumn{2}{|c|}{ This work } & \multicolumn{2}{|c|}{ Ref. [3] } \\
\hline & & $\mathrm{X}_{\mathrm{Rh}}(\mathrm{Liq})$ & $\mathrm{T}(\mathrm{K})$ & $\mathrm{X}_{\mathrm{Rh}}(\mathrm{Liq})$ & $\mathrm{T}(\mathrm{K})$ \\
\hline $\mathrm{L} \leftrightarrow(\mathrm{Li})+\mathrm{LiRh}$ & Eutectic & 0.0073 & 451.3 & $\approx 0$ & 453.0 \\
\hline $\mathrm{L} \leftrightarrow \mathrm{LiRh}$ & Congruent & 0.5 & 2147.4 & 0.5 & 2163.0 \\
\hline $\mathrm{L} \leftrightarrow \mathrm{LiRh}+\mathrm{LiRh}_{3}$ & Eutectic & 0.705 & 1913.3 & $\approx 0.7$ & 1893.0 \\
\hline $\mathrm{L} \leftrightarrow \mathrm{LiRh}_{3}$ & Congruent & 0.75 & 1924.7 & 0.75 & 1933.0 \\
\hline $\mathrm{L} \leftrightarrow \mathrm{Rh}+\mathrm{LiRh}_{3}$ & Eutectic & 0.819 & 1896.0 & $\approx 0.8$ & 1843.0 \\
\hline
\end{tabular}

TABLE IV: ENTHALPIES OF FORMATION OF INTERMETALLIC COMPOUNDS IN THE LI-RH AND TL-TM SYSTEMS IN KJ/MOLQ

\begin{tabular}{cccc}
\hline \hline Phase & $\begin{array}{c}\text { first principles calculations } \\
\text { this Work }\end{array}$ & $\begin{array}{c}\text { Calphad } \\
\text { This Work }\end{array}$ & $\begin{array}{c}\text { Miedema Model } \\
{[9]}\end{array}$ \\
\hline $\mathrm{LiRh}$ & -17.3319 & -17.481 & -20.0 \\
$\mathrm{LiRh}$ & -12.7246 & -12.009 & -13.0 \\
$\mathrm{Tl}_{3} \mathrm{Tm}$ & -13.1193 & -13.340 & \\
$\mathrm{TlTm}_{\mathrm{T}}$ & -22.8245 & -22.434 & \\
$\mathrm{Tl}_{3} \mathrm{Tm}_{5}$ & -22.7717 & -22.771 & \\
\hline \hline
\end{tabular}

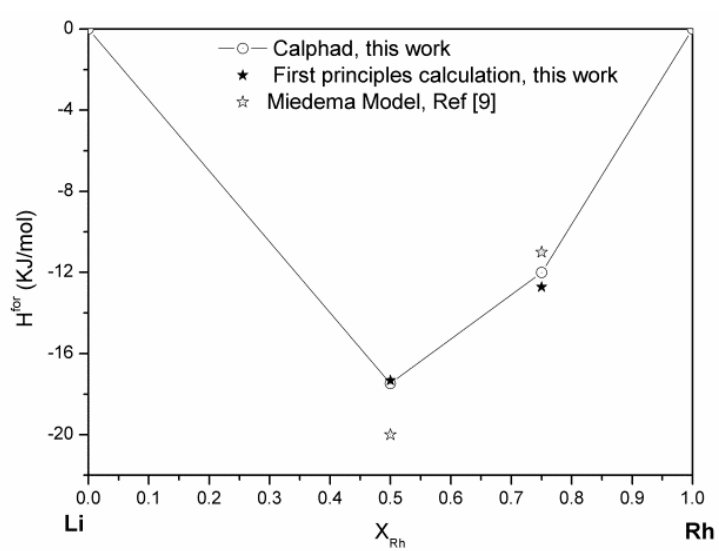

Fig. 4. Enthalpies of formation of intermetallicphases in the Li-Rh system. 


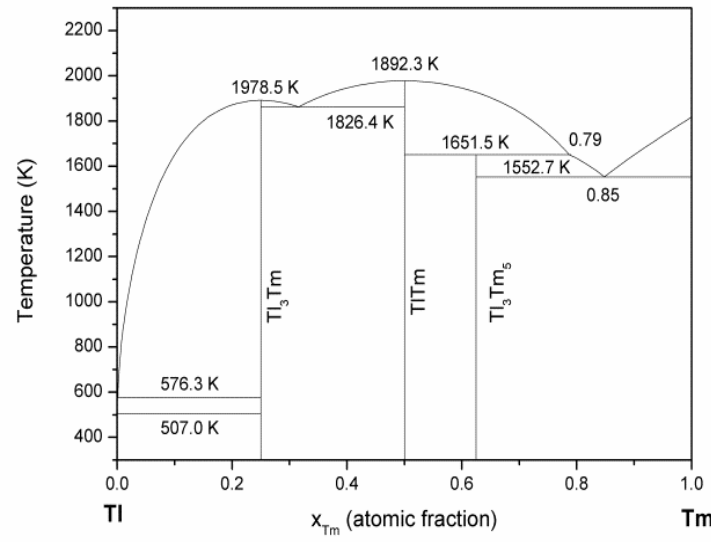

Fig. 5. Calculated phase diagram of the Tl-Tm system.

TABLE V: THE INVARIANT REACTIONS IN THE TL-TM SYSTEM

\begin{tabular}{|c|c|c|c|c|c|}
\hline \multirow[b]{2}{*}{ Reaction } & \multirow{2}{*}{$\begin{array}{l}\text { Type of } \\
\text { reaction }\end{array}$} & \multicolumn{2}{|c|}{ This work } & \multicolumn{2}{|c|}{ Ref. [4] } \\
\hline & & $\begin{array}{l}\mathrm{X}_{\mathrm{Rh}} \\
(\mathrm{Liq})\end{array}$ & $\mathrm{T}(\mathrm{K})$ & $\begin{array}{l}X_{\mathrm{Rh}} \\
(\mathrm{Liq})\end{array}$ & $\mathrm{T}(\mathrm{K})$ \\
\hline $\begin{array}{l}(\beta \mathrm{Tl}) \leftrightarrow(\alpha \mathrm{Tl}) \\
+\mathrm{Tl}_{3} \mathrm{Tm}\end{array}$ & Eutectoid & 0.00 & 507.0 & $\approx 0.0$ & 503.0 \\
\hline $\mathrm{L} \leftrightarrow(\alpha \mathrm{Tl})+\mathrm{Tl}_{3} \mathrm{Tm}$ & Eutectic & 0.0044 & 576.3 & $\approx 0.0$ & 573.0 \\
\hline $\mathrm{L} \leftrightarrow \mathrm{Tl}_{3} \mathrm{Tm}$ & Congruent & 0.25 & 1892.3 & 0.25 & 1893.0 \\
\hline $\mathrm{L} \leftrightarrow \mathrm{Tl}_{3} \mathrm{Tm}+\mathrm{TlTm}$ & Eutectic & 0.32 & 1826.4 & $\approx 0.35$ & 1723.0 \\
\hline $\mathrm{L} \leftrightarrow \mathrm{TlTm}$ & Congruent & 0.5 & 1978.5 & 0.5 & 1983.0 \\
\hline $\mathrm{L}+\mathrm{TlTm} \leftrightarrow \mathrm{Tl}_{3} \mathrm{Tm}_{5}$ & Peritectic & 0.75 & 1651.5 & $\approx 0.79$ & 1663.0 \\
\hline $\mathrm{L} \leftrightarrow \mathrm{Tl}_{3} \mathrm{Tm}_{5}+\mathrm{Tm}$ & Eutectic & 0.85 & 1552.7 & $\approx 0.87$ & 1563.0 \\
\hline
\end{tabular}

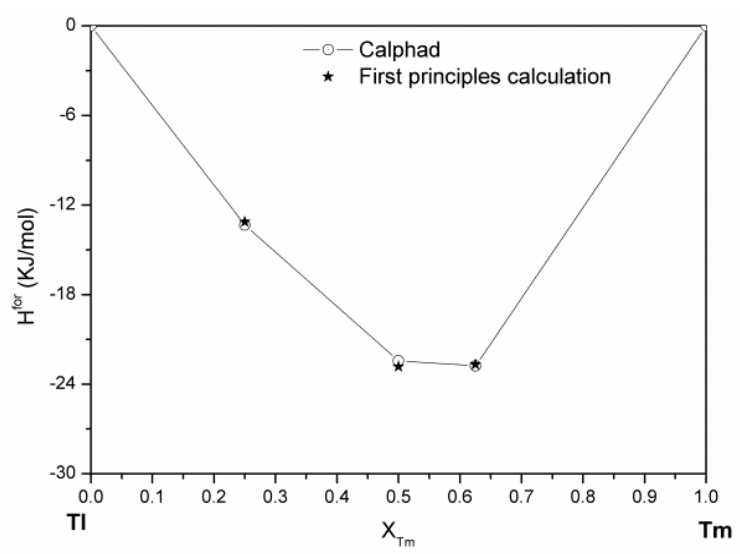

Fig. 6. Enthalpies of formation of intermetallicphases in the Tl-Tm system.

\section{CONCLUSION}

The Tl-Tm and Li-Rh systems have been assessed for the first time. The enthalpies of formation of intermetallic phases in the two systems are determined via first principles calculations and used in the assessment of these systems. A consistent set of thermodynamic parameters from various thermodynamic models has been obtained, for each solution phase and intermetallic compounds in the Tl-Tm and $\mathrm{Li}-\mathrm{Rh}$ binary systems. Due to the scarcity of the experimental data, further experimental investigations are desirable.

\section{REFERENCES}

[1] Z. Xia, Z. Chen, Y. Shi, N. Mu, and N. Sun, "Effect of rare earth element additions on the microstructure and mechanical properties of tin-silver-bismuth solder," Journal of Electronic Materials, vol. 31, pp. 564-567, 2002.

[2] N. Saunders and A. P. Miodownik, CALPHAD, Calculation of Phase Diagrams, A Comprehensive Guide, Pergamon, 1998, pp. 7-26.

[3] J. Sangster and A. Pelton, "The Li-Rh (lithium-rhodium) system," $J$. Phase Equilibria, vol. 12, pp. 682-684, 1991.

[4] T. B. Massalski and O. Okamoto, Binary Alloy Phase Diagrams, ASM International, Materials Park, Ohio, 1990, p. 2462, 3504.

[5] C. Magee, "A study of the synthesis and properties of the transition-metal hydryls," Final Report to the Joint US/EURATOM Research and Development Program. Contract No. AT (11-1)-1185, Denver Research Institute, University of Denver, EURAEC 1251, 1964.

[6] H. G. Wheat, C.-Y. Cheng, R. J. Bayuzick, R. W. Sullivan, and C. B Magee, "Compounds and phase relationships in the Li-RhSystem," $J$. Less-Common Met., vol. 58, pp. 13-29, 1978.

[7] H. C. Donkersloot and J. H. N. Van Vucht, "The crystal structure of IrLi, Ir3Li and LiRh3," J. Less-Common Met., vol. 50, pp. 279-282, 1976.

[8] S. S. Sidhu, K. D. Anderson, and D. D. Zauberis, "Neutron and X-ray diffraction study of LiRh," Acta Crystallogr, vol. 18, pp. 906-907, 1965.

[9] F. R. de Boer, R. Boom, W. C. M. Mattens, A. R. Miedema, and A. K. Niessen, Cohesion in Metals: Transition Metal Alloys, North-Holland Physics Publishing, Amsterdam, 1988, pp. 463.

[10] W. G. Moffatt, The Handbook of Binary Phase Diagrams, Genium Pub. Corp., Schenectady, N.Y. : General Electric, 1981, pp. 373.

[11] E. A. Franceschi and A. Palenzona, "The crystal structure of $\mathrm{RE}_{5} \mathrm{Ti}_{3}$ and $\mathrm{Y}_{5} \mathrm{Ti}_{3}$ compounds," J. Less-Common Met., vol. 18, pp. 93-98, 1969.

[12] J. L. J. Moriarty, J. E. Humphreys, R. O. Gordon, and N. C. Baenziger, "X-ray examination of some rare-earth-containing binary alloy systems," Acta Crystallographica, vol. 21, pp. 840-841, 1966.

[13] W. Kohn and L. J. Sham, "Self-consistent equations including exchange and correlation effects," Phys. Rev., vol. 140, pp. 1133-1138, 1965.

[14] G. Kresse and J. Furthmüller, "Efficient iterative schemes for ab initio total-energy calculations using a plane-wave basis set," Phys. Rev. B, vol. 54, pp. 11169-11186, 1996.

[15] G. Kresse and D. Joubert, "From ultrasoft pseudopotentials to the projector augmented-wave method," Phys. Rev. B, vol. 59, pp. $1758-1775,1999$.

[16] J. P. Perdew, K. Burke, and M. Ernzerhof, "Generalized gradient approximation made simple,” Phys. Rev. Lett.,vol. 77, pp. 3865-3868, 1996.

[17] H. J. Monkhorst and J. D. Pack, "Special points for Brillouin-zone integrations," Phys. Rev. B, vol. 13, pp. 5188-5192, 1976.

[18] A. T. Dinsdale, "SGTE data for pure elements," Calphad, vol. 15, pp. 317-425, 1991.

[19] O. Redlich and A. T. Kister, "Thermodynamics of nonelectrolyte solutions in a binary system," Ind. Eng. Chem, vol. 40, pp. 341-345, 1948.

[20] Y. Djaballah, "Modeling liquids and solid solutions of non-stoichiometric binary and ternary alloys," PhD thesis, Phyics Department, Batna University, Algeria, 2005.

[21] A. Belgacem-Bouzida, Y. Djaballah, and M. Notin, "Calorimetric measurement of the intermetallic compounds $\mathrm{Cr} 3 \mathrm{Ga}$ and $\mathrm{CrGa} 4$ and thermodynamic assessment of the (Cr-Ga) system," J. Alloys Comp. vol. 397, pp. 155-160, 2005.

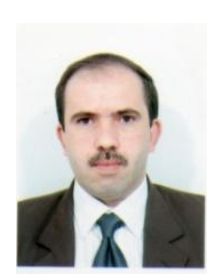

Yassine Djaballah received his $\mathrm{PhD}$ degree in materials science from Batna University, Algeria in 2005. He received the habilitation research from Batna University in 2010. He was an assistant professor at the Department of Physics, Batna University Algeria, from 2003 to 2010. He is currently a professor at the Physics Department, Batna University Algeria. His research interests are in materials science, thermodynamic modeling of multi component systems and ab-initio calculation of metallic alloys.

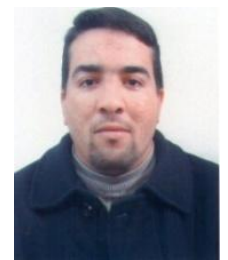

Ahmed Said Amer received his master degree in physics from Batna University, Algeria in 2010. He is currently a PhD student at the Physics Department, Batna University Algeria. His research interests are in materials science and the rmodynamic modeling of multi component. 
Sule Uğur received her $\mathrm{PhD}$ degree in physics from Gaz University, Turkey in 2004. She was an assistant professor at the Department of Physics, Gazi University from 2007 to 2010. She is currently an associate professor at the Physics Department, Gazi University Turkey. Her research interests are in the theoretical study of electronic structure, phase stability, and vibrational properties of compounds.

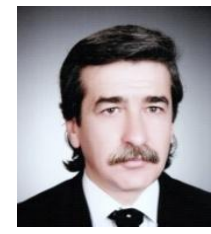

Gökay Ŭgur received his $\mathrm{PhD}$ degree in physics from Gazi University, Turkey in 1999. He was an associate professor at the Department of Physics, Gazi University from 2008 to 2013. He is currently a professor at the Physics Department, Gazi University Turkey. His research interests are in the theoretical study of electronic, elastic and phonon properties of compounds

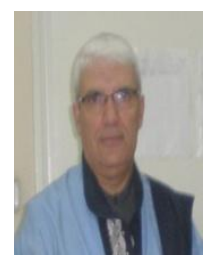

Aissa Belgacem-Bouzida received his $\mathrm{PhD}$ degree in materials science from Nancy University, France in 1989. He was an assistant professor at the Department of Physics, Batna University Algeria, from 1990 to 2005. He is currently a professor at the Physics Department, Batna University Algeria. His research interests are in the experimental study of phase diagrams and thermodynamic modeling of multi component systems. 